\title{
Hypoxic reoxygenation during initial reperfusion attenuates cardiac dysfunction and limits ischemia-reperfusion injury after cardioplegic arrest in a porcine model
}

\author{
U. Abdel-Rahman, MD, ${ }^{\text {a }}$ P. Risteski, MD, ${ }^{a}$ K. Tizi, ${ }^{a}$ S. Kerscher, MD, PhD, ${ }^{\text {b }}$ S. Bejati, ${ }^{a}$ K. Zwicker, MD, ${ }^{b}$ M. Scholz, MD, PhD, \\ U. Brandt, MD, PhD, ${ }^{b}$ and A. Moritz, MD, $\mathrm{PhD}^{\mathrm{a}}$
}

\begin{abstract}
Objective: In clinical practice, reperfusion of ischemic myocardium usually occurs under high arterial oxygen levels. However, this might aggravate cardiac ischemia-reperfusion injury caused by excessive oxidative stress. In an experimental in vivo study, the cardioprotective role of hypoxic reoxygenation during initial reperfusion was assessed.
\end{abstract}

\begin{abstract}
Methods: Twenty-one adult pigs were started on cardiopulmonary bypass with aortic crossclamping (90 minutes) and cardioplegic arrest. During initial reperfusion, 10 pigs underwent standard hypoxic reoxygenation $\left(\mathrm{PaO}_{2}, 250-350 \mathrm{~mm} \mathrm{Hg}\right)$, whereas gradual reoxygenation $\left(\mathrm{PaO}_{2}, 40-90 \mathrm{~mm} \mathrm{Hg}\right)$ was performed in 11 pigs. Cardiac function was analyzed by means of the thermodilution method and conductance catheter technique.
\end{abstract}

Results: In both groups cardiac index was decreased 10 minutes after cardiopulmonary bypass compared with preoperative values. Sixty minutes after cardiopulmonary bypass, cardiac index improved significantly after gradual reoxygenation compared with that after hypoxic reoxygenation $\left(3.2 \pm 0.6 \mathrm{vs} 2.5 \pm 0.5 \mathrm{~L} \cdot \mathrm{min}^{-1} \cdot \mathrm{m}^{-2}, P=\right.$ $.04)$. Correspondingly, end-systolic pressure-volume relationship and peak left ventricular pressure increase were significantly less decreased in the gradual reoxygenation group. During and after reperfusion, malondialdehyde and troponin $T$ values within the coronary sinus were significantly lower after gradual reoxygenation (60 minutes after declamping: malondialdehyde, $7.6 \pm 0.8$ vs $4.6 \pm 0.5 \mu \mathrm{mol} / \mathrm{L}[P=.007]$; troponin, $0.12 \pm 0.02$ vs $0.41 \pm$ $0.12 \mathrm{ng} / \mathrm{mL}[P=.02])$.

Conclusion: Hypoxic reoxygenation at the onset of reperfusion attenuates myocardial ischemia-reperfusion injury and helps to preserve cardiac performance after myocardial ischemia in a pig model.

Myocardial ischemia-reperfusion (IR) injury is a complex pathophysiologic process that is initiated at the very early moments of reperfusion and restoration of coronary blood flow after ischemia. The underlying mechanisms of myocardial IR injury have not been fully elucidated, and there are several factors playing an important role in the pathogenesis of IR injury. ${ }^{1,2}$ Clearly, one of the major contributors to myocardial IR injury is the rapid generation of free oxygen radicals during early reperfusion of the ischemic heart.

Although the pathogenic effects of hyperoxia on cellular metabolism are well known, ${ }^{3}$ the conventional method of conducting cardiopulmonary bypass (CPB) with cardiac arrest is to maintain high oxygen levels. The relationship between oxygen-induced radical production and impairment of myocardial energy metabolism, as well as myocardial dysfunction, after reperfusion was clearly shown. ${ }^{4-6}$ In addi-

From the Department of Thoracic and Cardiovascular Surgery ${ }^{\mathrm{a}}$ and the Centre of Biological Chemistry, Molecular Bioenergetics Group, ${ }^{b}$ Johann Wolfgang Goethe-University, Frankfurt/Main, Germany, and the Department of Trauma Surgery, ${ }^{\mathrm{c}}$ Heinrich-Heine-University, Düsseldorf, Germany.

Received for publication March 4, 2008; revisions received Aug 13, 2008; accepted for publication Sept 6, 2008.

Address for reprints: Ulf Abdel-Rahman, MD, Department of Thoracic and Cardiovascular Surgery, JW Goethe University, Theodor-Stern-Kai 7, D 60590 Frankfurt am

Main, Germany (E-mail: abdel-rahman@em.uni-frankfurt.de).

J Thorac Cardiovasc Surg 2009; 137:978-82

$0022-5223 / \$ 36.00$

Copyright (c) 2009 by The American Association for Thoracic Surgery

doi:10.1016/j.jtcvs.2008.09.025 tion, it could be demonstrated that oxidative stress aggravates postischemic myocardial stunning. ${ }^{7,8}$

Clinically, the issue of IR injury concerns both cardiac surgeons and cardiologists because of the fact that myocardial reperfusion injury occurs in a setting of global ischemia in cardiac surgery, as well as more regionally in patients undergoing percutaneous coronary interventions for acute ischemia. Recently evolving postconditioning strategies describe multiple cardioprotective modalities to attenuate IR injury whereby hypoxic postconditioning reduces reoxygenation-induced injury. ${ }^{9,10}$ However, there is still a lack of experimental in vivo studies investigating the effect of such cardioprotective strategies on cardiac function in complex heart surgery, as well as interventional cardiology, with the aim of routine clinical application. ${ }^{11}$

The present porcine in vivo study uses hypoxic reoxygenation (HR) to limit myocardial IR injury. We hypothesize that gradual reoxygenation (GR) on aortic declamping reduces IR injury after prolonged myocardial ischemia caused by decreased oxidative stress and myocardial injury.

\section{MATERIALS AND METHODS Study Design}

We used an acute porcine model of CPB with 90 minutes of aortic clamping and cardioplegic arrest, 30 minutes of reperfusion, and 60 minutes of observation time. 


$$
\begin{aligned}
& \text { Abbreviations and Acronyms } \\
& \begin{aligned}
\mathrm{CPB}= & \text { cardiopulmonary bypass } \\
\mathrm{EDPVR}= & \text { end-diastolic pressure-volume } \\
& \text { relationship } \\
\mathrm{ESPVR}= & \text { end-systolic pressure-volume } \\
& \text { relationship } \\
\mathrm{GR}= & \text { gradual reoxygenation } \\
\mathrm{HR}= & \text { hypoxic reoxygenation } \\
\mathrm{IR}= & \text { ischemia-reperfusion } \\
\mathrm{MDA}= & \text { malondialdehyde }
\end{aligned}
\end{aligned}
$$

Twenty-one German landrace pigs were operated on with a mean body weight of $47.8 \pm 3.5 \mathrm{~kg}$. The animals were randomly divided into 2 groups. Ten pigs underwent HR ( $\mathrm{PaO} 2,250-350 \mathrm{~mm} \mathrm{Hg}$ ) according to usual standards during the first 10 minutes of reperfusion. In 11 pigs GR was started for 2 minutes at hypoxic levels $\left(\mathrm{PaO}_{2}, 40-50 \mathrm{~mm} \mathrm{Hg}\right)$ before declamping and continued for a consecutive 10 minutes at higher oxygen levels $\left(\mathrm{PaO}_{2}, 50-90\right.$ $\mathrm{mm} \mathrm{Hg}$ ) after aortic declamping. After the first 10 minutes of reperfusion, normoxic conditions were established again in both groups.

\section{Experimental Setting}

The animals were premedicated with intramuscular application of ketamine (30 mg/kg; Ketavest; Pharmacia, Erlangen, Germany), xylazine (2 $\mathrm{mg} / \mathrm{kg}$; Rompun; Bayer AG, Leverkusen, Germany), and midazolam (0.1 $\mathrm{mg} / \mathrm{kg}$; Dormicum; Roche Pharma AG, Reinach, Switzerland). General anesthesia and relaxation were achieved by administering fentanyl $(1.5 \mu \mathrm{g}$. $\mathrm{kg}^{-1} \cdot \mathrm{h}^{-1}$; B. Braun AG, Melsungen, Germany), propofol ( $2 \mathrm{mg} / \mathrm{kg}$ for initiation and $10 \mu \mathrm{g} \cdot \mathrm{kg}^{-1} \cdot \mathrm{h}^{-1}$ for maintenance; Disoprivan $2 \%$; Astra Zeneca GmbH, Wedel, Germany), and pancuronium (0.1-0.2 $\mathrm{mg} \cdot \mathrm{kg}^{-1}$. $\mathrm{h}^{-1}$; Curamed Pharma GmbH, Karlsruhe, Germany).

After tracheotomy, the pigs were started on a volume-controlled respirator (EVITA 2; Fa. Dräger, Lübeck, Germany). The left internal jugular vein and left femoral artery were dissected for catheter placement. A thermodilution catheter (Baxter Healthcare Corp, Edwards Division, Santa Ana, Calif) was placed through the right internal jugular vein and advanced through the right atrium into the pulmonary artery. A cardiac output monitor (Model 9520A; Baxter Healthcare Corp, Edwards Division) was used for hemodynamic assessment. The conductance catheter was inserted through the right carotid artery and positioned through the aortic valve in the apex of the left ventricle. Data were evaluated with a Cardiac Function Analyzer (Leycom CFA-512; Leyden, The Netherlands). Monitoring included electrocardiography and arterial blood pressure, central venous pressure, pulmonary artery pressure, and blood temperature measurement (Marquette Solar 8000; GE Yorkshire, United Kingdom). Arterial blood gas, electrolyte, and hemoglobin levels were determined with a blood gas analyzer (Blood Gas System 288; CibaCorning, Medfield, Mass). Blood gases were maintained at physiologic $\mathrm{pH}$, $\mathrm{PaCO}_{2}$ at 30 to $40 \mathrm{~mm} \mathrm{Hg}$, and $\mathrm{PaO}_{2}$ at 90 to $120 \mathrm{~mm} \mathrm{Hg}$ before and after CPB.

After induction of anesthesia and instrumentation, median sternotomy was performed in the usual manner. After opening of the pericardium, the left anterior descending coronary artery was dissected in its middle segment, and a 2.0-mm flow probe was placed (Transonic T206; Transonic Systems, Inc, Ithaca, NY) for coronary flow measurements with an ultrasound device (Transonic Flow-QC; Transonic Systems, Inc). A coronary sinus catheter was placed for taking blood samples.

The study protocol was approved by the Committee for Animal Research at the JW Goethe University, Frankfurt/Main, Germany. The study was performed according to the guidelines for animal experiments in Germany (Operative Eingriffe bei Versuchstieren formulated by the German Society for Animal Science and the "Guide for the care and use of laboratory animals" prepared by Gesellschaft für Versuchstierkunde, published 2001).

\section{Cardiopulmonary Bypass}

Systemic heparinization was administered (350 IU/kg body weight; Liquemin Roche, Grenzach-Wyhlen, Germany), and activated coagulation time during CPB was adjusted to greater than 400 seconds (Hemo Tec, Inc, Eaglewood, Colo). The aorta and right atrium were cannulated with an $18 \mathrm{~F}$ flexible arterial cannula (Medtronic AG, Düsseldorf, Germany) and a 32F 2-stage venous cannula (DLP, Medtronic AG). A complete preconnected tubing set with membrane oxygenator (HILITE 7000) and cardiotomy reservoir (MV420; Medos Medizintechnik AG, Stolberg, Germany) was used with a standard roller pump (Fa. Stöckert). Priming volume consisted of Ringer solution $(1600 \mathrm{~mL}$ ) and $5000 \mathrm{IU}$ of heparin. During $\mathrm{CPB}$, arterial oxygen levels were continuously measured with an inline oxygen determination device (CDI 500; Cardiovascular Devices, Inc, Irvine, Calif).

All animals were started on normothermic $\left(36^{\circ} \mathrm{C}-38^{\circ} \mathrm{C}\right) \mathrm{CPB}$ for 120 minutes. After aortic crossclamping of 90 minutes, animals were weaned from CPB after 30 minutes of reperfusion. Cardiac arrest was initially achieved by means of a 2-minute antegrade infusion of warm blood cardioplegic solution, as described by Calafiore and colleagues, ${ }^{12}$ and repeated every 20 minutes. Perfusion pressure during CPB was maintained at 50 to $60 \mathrm{~mm} \mathrm{Hg}$. After 30 minutes of reperfusion and weaning from CPB, an observation period of 60 minutes followed for hemodynamic measurements and taking blood samples, as mentioned below. At the end of the experiment, animals were killed.

\section{End Points}

Hemodynamic parameters. At steady-state conditions, the following parameters were measured before and 10, 30, and 60 minutes after CPB by using the thermodilution method: cardiac index, systemic vascular resistance index, pulmonary vascular resistance index, left ventricular stroke work index, and left ventricular end-diastolic pressure.

By using the conductance catheter technique, left ventricular performance was evaluated by determining the following parameters ${ }^{13}$ : end-systolic pressure-volume relationship (ESPVR, end-diastolic pressure-volume relationship (EDPVR), and peak left ventricular pressure increase. The ESPVR and EDPVR were obtained from reduction of the preload by intermittent vena caval occlusion in a linear model. The conductance catheter system was calibrated by means of injection of hypertonic saline into the pulmonary artery.

Coronary blood flow. Coronary flow measurements of the left anterior descending coronary artery were performed before and 10, 30, and 60 minutes after CPB.

Number of defibrillations. During the reperfusion period of 30 minutes, the number of defibrillations was assessed. In case of ventricular fibrillation, the heart was defibrillated with $10 \mathrm{~J}$ (Lifepack 9; Physio-Control Corp, Redmond, Wash).

Myocardial ischemic damage. The troponin $T$ concentration was assessed in micrograms per liter (Roche Diagnostics $\mathrm{GmbH}$, Mannheim, Germany) in the coronary sinus blood before CPB and 20 and 60 minutes after aortic declamping.

Oxidative stress (lipid peroxidation). The concentration of malondialdehyde (MDA) in coronary sinus blood was assessed in blood samples obtained before $\mathrm{CPB}$, as well as 10,20 , and 60 minutes after aortic declamping. Blood was stored on ice before centrifugation $\left(4^{\circ} \mathrm{C}\right.$ and $2500 \mathrm{~g}$ for 10 minutes) for a maximum of 10 minutes in precooled ethylenediamine tetra-acetic acid tubes. Plasma samples were rapidly frozen at $-80^{\circ} \mathrm{C}$ for later analysis. Two hundred microliters of plasma supernatant was used to determine MDA levels by using a spectrophotometric method with the Lipid Peroxidation Assay Kit (Calbiochem, San Diego, Calif).

\section{Statistics}

Statistical analysis was performed by using the BIAS software package (version 8.4.2) provided by Johann Wolfgang Goethe University, Frankfurt/ Main, Germany. Differences between groups were tested with a 2-tailed 
TABLE 1. Hemodynamic parameters

\begin{tabular}{|c|c|c|c|c|c|c|c|c|c|}
\hline & \multicolumn{2}{|c|}{ Before CPB } & \multicolumn{2}{|c|}{10 Min after CPB } & \multicolumn{2}{|c|}{30 Min after CPB } & \multicolumn{2}{|c|}{60 Min after CPB } & \multirow[b]{2}{*}{$P$ value } \\
\hline & HR & GR & HR & GR & HR & GR & HR & GR & \\
\hline $\mathrm{CI}\left(\mathrm{L} \cdot \mathrm{min}^{-1} \cdot \mathrm{m}^{-2}\right)$ & $3.2 \pm 0.6$ & $3.1 \pm 0.7$ & $2.8 \pm 0.5$ & $3.0 \pm 0.8$ & $2.6 \pm 0.5$ & $3.1 \pm 0.8$ & $2.5 \pm 0.5$ & $3.2 \pm 0.6$ & .04 \\
\hline HR (beats/min) & $85 \pm 5$ & $82 \pm 5$ & $93 \pm 6$ & $95 \pm 6$ & $94 \pm 7$ & $93 \pm 5$ & $95 \pm 8$ & $91 \pm 5$ & .5 \\
\hline $\mathrm{dP} / \mathrm{dt}_{\max }\left(\mathrm{mm} \mathrm{Hg} \cdot \mathrm{s}^{-1} \cdot \mathrm{m}^{-2}\right)$ & $2085 \pm 299$ & $2116 \pm 211$ & $1445 \pm 212$ & $1503 \pm 245$ & $1490 \pm 219$ & $1763 \pm 262$ & $1518 \pm 229$ & $1820 \pm 285$ & .02 \\
\hline LVSWI $\left(\mathrm{Kg} \cdot \mathrm{m}^{-2}\right)$ & $28.9 \pm 1.6$ & $30.2 \pm 1.2$ & $17.9 \pm 2.1$ & $17.7 \pm 2.2$ & $15.5 \pm 2.2$ & $20.1 \pm 2.4$ & $15.8 \pm 2.4$ & $21.4 \pm 2.3$ & .1 \\
\hline $\operatorname{ESPVR}\left(\mathrm{mm} \mathrm{Hg} \cdot \mathrm{mL}^{-1}\right)$ & $2.05 \pm 0.6$ & $2.11 \pm 0.5$ & $1.59 \pm 0.6$ & $1.66 \pm 0.5$ & $1.65 \pm 0.5$ & $1.81 \pm 0.5$ & $1.62 \pm 0.5$ & $1.85 \pm 0.6$ & .01 \\
\hline $\operatorname{EDPVR}\left(\mathrm{mm} \mathrm{Hg} \cdot \mathrm{mL}^{-1}\right)$ & $7.89 \pm 1.1$ & $7.71 \pm 1.2$ & $5.77 \pm 1.6$ & $5.93 \pm 1.4$ & $5.90 \pm 1.6$ & $6.23 \pm 1.5$ & $5.88 \pm 1.8$ & $6.34 \pm 1.2$ & .08 \\
\hline LVEDP (mm Hg) & $9.7 \pm 1.4$ & $10.2 \pm 1.1$ & $11.0 \pm 1.6$ & $11.7 \pm 1.7$ & $12.9 \pm 1.7$ & $12.2 \pm 1.3$ & $14.4 \pm 1.4$ & $12.3 \pm 1.5$ & .03 \\
\hline SVRI (dyn $\left.\cdot \mathrm{sec} \cdot \mathrm{cm}^{-5} \cdot \mathrm{m}^{-2}\right)$ & $1666 \pm 109$ & $1744 \pm 60$ & $1061 \pm 127$ & $1029 \pm 83$ & $1095 \pm 115$ & $970 \pm 70$ & $1223 \pm 121$ & $960 \pm 97$ & .1 \\
\hline PVRI (dyn $\cdot \mathrm{sec} \cdot \mathrm{cm}^{-5} \cdot \mathrm{m}^{-2}$ ) & $223 \pm 12$ & $213 \pm 19$ & $303 \pm 39$ & $237 \pm 22$ & $314 \pm 41$ & $273 \pm 21$ & $339 \pm 32$ & $309 \pm 21$ & .5 \\
\hline
\end{tabular}

$C P B$, Cardiopulmonary bypass; $H R$, hypoxic reoxygenation; $G R$, gradual reoxygenation; $C I$, cardiac index; $H R$, heart rate; $d P / d t_{\max }$, peak left ventricular pressure increase; $L V S W I$, left ventricular stroke work index; $E S P V R$, end-systolic pressure-volume relationship; $E D P V R$, end-diastolic pressure-volume relationship; $L V E D P$, left ventricular end-diastolic pressure; SVRI, systemic vascular resistance index; PVRI, pulmonary vascular resistance index.

Wilcoxon-Mann-Whitney $U$ test. Significance of multiple comparisons between groups was determined with multivariate analyses by using the Hotel$\operatorname{ling} t^{2}$ test. The data are expressed as the mean \pm standard error of the mean.

\section{RESULTS}

Of 27 pigs, only 21 could be included in the study. In 6 cases early termination of the experiment was required: 2 pigs had pericarditis, 2 had myocardial infarction caused by preoperative stress, 1 had an aortic dissection caused by cannulation, and 1 had a bleeding complication. Body weight and body surface area did not differ between the HR group $(\mathrm{n}=10)$ and the GR group $(\mathrm{n}=11$; body weight, $47.3 \pm 3.6 \mathrm{vs} 48.2 \pm 3.4 \mathrm{~kg}$; body surface area, $1.19 \pm 0.04$ vs $1.20 \pm 0.04 \mathrm{~m}^{2}$ ).

\section{Cardiac Function and Hemodynamic Parameters}

Generally, all parameters of myocardial performance showed a marked decrease 10 minutes after CPB in both groups; however, 30 and 60 minutes after the end of CPB, these parameters improved again after GR, whereas they remained at a low level in the HR group (Table 1). Sixty minutes after CPB, cardiac index reached preoperative levels in the GR group, whereas values further decreased after HR, showing a significant difference $(3.2 \pm 0.6$ vs $2.5 \pm 0.5$ $\left.\mathrm{L} \cdot \min ^{-1} \cdot \mathrm{m}^{-2}, P=.04\right)$. The left ventricular stroke work index also tended to recover better after GR compared with $\mathrm{HR}$ at 60 minutes after CPB without reaching statistical significance. Correspondingly, ESPVR and peak left ventricular pressure increase displayed a continuous increase in both groups; however, there was a significant difference between groups 60 minutes after $\mathrm{CPB}$, with a better systolic performance in the GR group. Values of EDPVR and left ventricular end-diastolic pressure showed less diastolic dysfunction and myocardial stiffness after GR. The values for systemic vascular resistance index displayed a tendency to be constantly lower in the GR group than in the HR group during the observation period. Pulmonary vascular resistance index showed a marked increase after HR 10 minutes after CPB compared with GR, with a constant increase in both groups up to the end of the observation period.

\section{Coronary Flow}

Coronary flow was increased significantly in both groups 10 minutes after $\mathrm{CPB}$ compared with preoperative values, without exhibiting a significant difference between groups.

\section{Defibrillation}

After aortic declamping, more defibrillations were required after HR compared with after GR (number of defibrillations, $3.0 \pm 2.0$ vs $1.7 \pm 0.9 ; P=.07)$.

\section{Troponin T}

In both groups troponin $\mathrm{T}$ values increased continuously after aortic declamping, but the increase was markedly pronounced in the HR group. Statistically significant differences between groups were observed 20 and 60 minutes after declamping (eg, 60 minutes: $0.12 \pm 0.02$ vs $0.41 \pm$ $0.12 \mathrm{ng} / \mathrm{mL} ; P=.02$; Figure 1).

\section{Lipid Peroxidation}

After aortic declamping, MDA levels increased continuously in the HR group throughout the measurements, reaching the highest values after 60 minutes. After GR, MDA values increased only slightly during early reperfusion and decreased 60 minutes after aortic declamping, reaching a significant difference between groups $(7.6 \pm 0.8$ vs $4.6 \pm 0.5$ $\mu \mathrm{mol} / \mathrm{L}, P=.007$, Figure 2).

\section{DISCUSSION}

Myocardial reperfusion has been referred to as a doubleedged sword because reperfusion itself can lead to accelerated and additional myocardial injury beyond that generated by ischemia alone. ${ }^{14}$ In times of challenging high-risk patients requiring complex cardiac surgery, CPB with prolonged cardiac arrest reduction of cardiac damage 


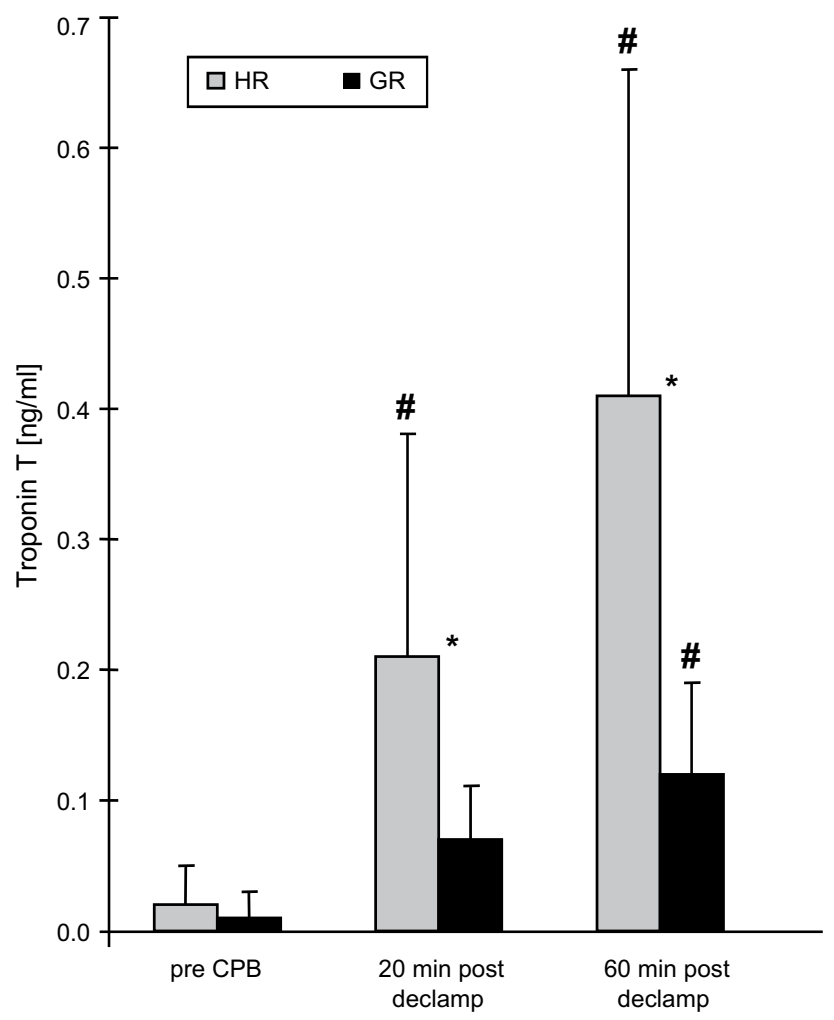

FIGURE 1. Troponin T: serum levels from coronary sinus blood. Compared with preoperative values, troponin $\mathrm{T}$ concentrations were significantly increased at 20 and 60 minutes after aortic declamping in both the hypoxic reoxygenation $(H R)$ and gradual reoxygenation $(G R)$ groups; however, this increase was almost 4-fold larger in the HR group. Data are presented as the mean \pm standard error of the mean. *Significant differences between groups $(P<.05)$. \#Significant differences from preoperative values $(P<.05) . C P B$, Cardiopulmonary bypass.

is of key interest. However, cardiac arrest inevitably means global myocardial ischemia followed by reperfusion after restoration of coronary flow at the end of the procedure. Similar phenomena occur when target vessels are revascularized in the treatment of acute myocardial ischemia.

There is general agreement that oxygen free radicals are involved in postischemic contractile dysfunction. ${ }^{15}$ Especially at the onset of reoxygenation, free radical production can overwhelm the endogenous scavenging capacity. Lipid peroxidation associated with oxidative stress has been proposed to directly contribute to cardiac arrhythmias and fibrillation. ${ }^{16}$ In the 1980 s, Buckberg ${ }^{17}$ popularized the concept of reperfusion injury and described the rationale of normoxia during CPB, resulting in improved cardiac function after normoxic reperfusion of ischemic myocardium. Limiting oxygen pressure at reperfusion limits oxygen radical production by reducing substrate availability, thereby promoting resumption of cell membrane pump function and allowing restoration of normal intracellular and extracellular physiology. ${ }^{17}$

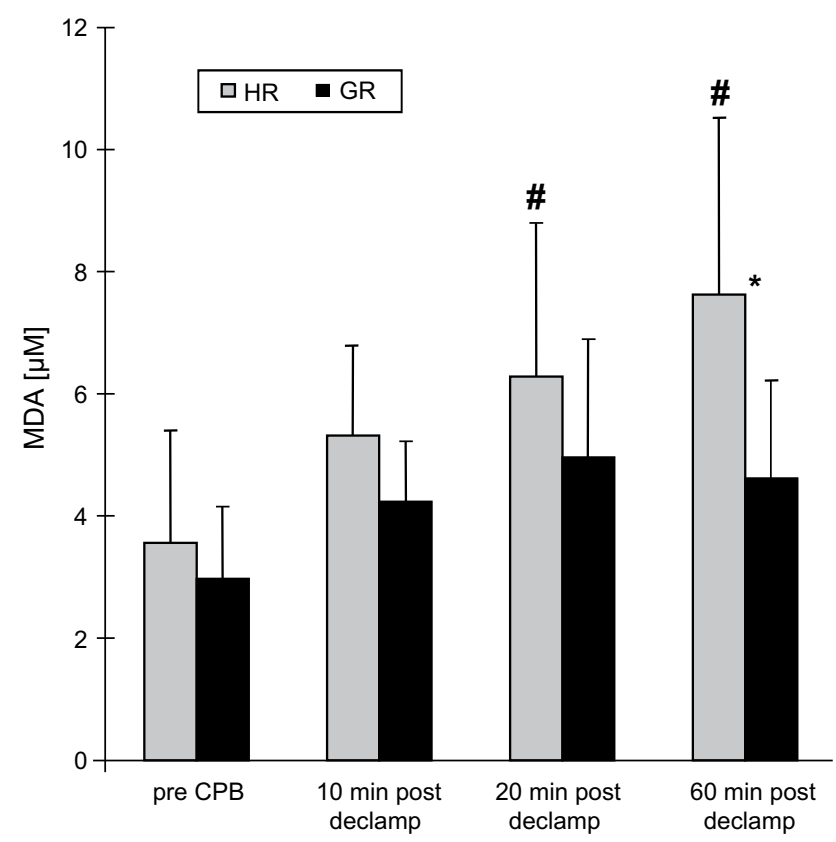

FIGURE 2. Lipid peroxidation: malondialdehyde (MDA) concentrations measured in coronary sinus blood samples. Compared with preoperative values, a significant increase in MDA concentrations was observed at 20 and 60 minutes after aortic declamping only in the hypoxic reoxygenation $(H R)$ group. *Significant differences between groups $(P<.05)$. \#Significant differences from preoperative values $(P<.05)$. $C P B$, Cardiopulmonary bypass; $G R$, gradual reoxygenation.

In our in vivo pig model, it could be observed that GR leads to significantly less impairment of cardiac function, reduced myocardial injury, and decreased lipid peroxidation consistent with less severe oxidative stress.

At the end of the observation period, almost all physiologic and hemodynamic parameters investigated in this study (cardiac function, coronary flow, and number of defibrillations) were significantly better after GR in contrast to those after HR. It is well known that CPB with or without cardiac arrest leads to significant depression of systolic and diastolic left ventricular function, according to the conductance catheter technique. ${ }^{18,19}$ Based on the present results, it is obvious that GR after prolonged myocardial ischemia has a beneficial effect on postoperative cardiac and hemodynamic performance. Especially systolic function was better preserved, and diastolic performance was less impaired. Moreover, recurrent episodes of ventricular fibrillation during reperfusion, indicating a more disturbed ionic homeostasis based on increased intramyocyte sodium content, ${ }^{20}$ were less frequently observed after the GR protocol.

Results of the present study also indicate that oxidative stress during HR leads to markedly increased MDA production in the early reperfusion period, confirming earlier findings. $^{21,22}$ Normoxic conditions during CPB might limit lipid peroxidation compared with hyperoxemia in adults undergoing cardiac surgery. ${ }^{23,24}$ 


\section{CONCLUSION}

In the early onset of myocardial reperfusion, hypoxic conditions lead to severe IR injury in terms of increased oxidative stress and consequently decreased cardiac function. In contrast, GR results in significantly reduced oxidative and myocardial damage and significantly less impaired cardiac performance in the present in vivo pig model. Therefore HR during initial reperfusion, in the context of other preventive or therapeutic cardiac interventions, is likely to be beneficial in terms of cardioprotection. However, clinical evaluation of appropriate reoxygenation strategies in diseased patients is recommended.

\section{References}

1. Carden DL, Granger DN. Pathophysiology of ischaemia-reperfusion injury. J Pathol. 2000;190:255-66.

2. Piper HM, Abdallah Y, Schafer C. The first minutes of reperfusion: a window of opportunity for cardioprotection. Cardiovasc Res. 2004;61:365-71.

3. Frank L, Massaro D, Oxygen-toxicity. Am J Med. 1980;69:117-26.

4. Ambrosio G, Zweier JL, Flaherty JT. The relationship between oxygen radical generation and impairment of myocardial energy metabolism following postischemic reperfusion. J Mol Cell Cardiol. 1991;23:1359-74.

5. Prasad K, Bharadwaj B, Kalra J. Oxyradicals and cardiac stunning during aortocoronary bypass-surgery. J Mol Cell Cardiol. 1992;24(suppl):S17.

6. Matheis G, Sherman MP, Buckberg GD, Haybron DM, Young HH, Ignarro LJ. Role of L-arginine-nitric oxide pathway in myocardial reoxygenation injury 3. Am J Physiol Heart Circ Physiol. 1992;262:H616-20.

7. Bolli R. Oxygen-derived free-radicals and postischemic myocardial dysfunction (stunned myocardium). J Am Coll Cardiol. 1988;12:239-49.

8. Cesselli D, Jakoniuk I, Barlucchi L, Beltrami AP, Hintze TH, Nadal-Ginard B, et al. Oxidative stress-mediated cardiac cell death is a major determinant of ventricular dysfunction and failure in dog dilated cardiomyopathy. Circ Res. 2001;89: 279-86.

9. Sun HY, Wang NP, Kerendi F, Halkos M, Kin H, Guyton RA, et al. Hypoxic postconditioning reduces cardiomyocyte loss by inhibiting ROS generation and intracellular Ca2+overload. Am J Physiol Heart Circ Physiol. 2005;288:H1900-8.

10. Zhao ZQ, Vinten-Johansen J. Postconditioning: reduction of reperfusion-induced injury. Cardiovasc Res. 2006;70:200-11.
11. Bolli R, Becker L, Gross G, Mentzer R Jr, Balshaw D, Lathrop DA. Myocardial protection at a crossroads: the need for translation into clinical therapy. Circ Res. 2004;95:125-34.

12. Calafiore AM, Teodori G, Mezzetti A, Bosco G, Verna AM, Di Giammarco G, et al. Intermittent antegrade warm blood cardioplegia. Ann Thorac Surg. 1995; 59:398-402.

13. Baan J, van der Velde ET, de Bruin HG, Smeenk GJ, Koops J, van Dijk AD, et al. Continuous measurement of left ventricular volume in animals and humans by conductance catheter 1. Circulation. 1984;70:812-23.

14. Braunwald E, Kloner RA. Myocardial reperfusion: a double-edged sword? J Clin Invest. 1985;76:1713-9.

15. Gross GJ, Kersten JR, Warltier DC. Mechanisms of postischemic contractile dysfunction. Ann Thorac Surg. 1999;68:1898-904.

16. Meerson FZ, Belkina LM, Sazontova TG, Saltykova VA, Arkhipenko Y. The role of lipid peroxidation in pathogenesis of arrhythmias and prevention of cardiac fibrillation with antioxidants. Basic Res Cardiol. 1987;82:123-37.

17. Buckberg GD. Studies of hypoxemic/reoxygenation injury. 1. Linkage between cardiac-function and oxidant damage. J Thorac Cardiovasc Surg. 1995;110: 1164-70.

18. Wallace A, Lam HW, Nose PS, Bellows W, Mangano DT. Changes in systolic and diastolic ventricular function with cold cardioplegic arrest in man. The Multicenter Study of Perioperative Ischemia (McSPI) Research Group. J Card Surg. 1994;9(suppl):S497-502.

19. Aybek T, Kahn MF, Dogan S, Abdel-Rahman U, Mierdl S, Kessler P, et al. Cardiopulmonary bypass impairs left ventricular function determined by conductance catheter measurement. Thorac Cardiovasc Surg. 2003;51:301-5.

20. Holman WL, Skinner JL, Killingsworth CR, Rogers JM, Melnick S, Ideker RE, et al. Controlled postcardioplegia reperfusion: mechanism for attenuation of reperfusion injury. J Thorac Cardiovasc Surg. 2000;119:1093-101.

21. Royston D, Fleming JS, Desai JB, Westaby S, Taylor KM. Increased production of peroxidation products associated with cardiac operations-evidence for freeradical generation. J Thorac Cardiovasc Surg. 1986;91:759-66.

22. Prasad K, Kalra J, Bharadwaj B, Chaudhary AK. Increased oxygen free-radical activity in patients on cardiopulmonary bypass undergoing aortocoronary bypass-surgery. Am Heart J. 1992;123:37-45.

23. Ihnken K, Winkler A, Schlensak C, Sarai K, Neidhart G, Unkelbach U, et al. Normoxic cardiopulmonary bypass reduces oxidative myocardial damage and nitric oxide during cardiac operations in the adult. J Thorac Cardiovasc Surg. 1998; 116:327-34.

24. Abdel-Rahman U, Aybek T, Moritz A, Kleine P, Matheis G. Graded reoxygenation limits lipid peroxidation during surgical reperfusion. Med Sci Monit. 2003;9: CR389-91. 